\title{
Facile Preparation of $\mathbf{g}-\mathrm{C}_{3} \mathrm{~N}_{4}-\mathrm{WO}_{3}$ Composite Gas Sensing Materials with Enhanced Gas Sensing Selectivity to Acetone
}

\author{
Xiangfeng Chu $\mathbb{D}^{1},{ }^{1}$ Junsong Liu, ${ }^{1}$ Shiming Liang $\mathbb{D},{ }^{2}$ Linshan Bai, ${ }^{1}$ Yongping Dong, \\ and Mauro Epifani $\mathbb{i D}^{3}$ \\ ${ }^{1}$ School of Chemistry and Chemical Engineering, Anhui University of Technology, Maanshan 243002, China \\ ${ }^{2}$ School of Materials Science and Engineering, Linyi University, Linyi 276005, China \\ ${ }^{3}$ Consiglio Nazionale delle Ricerche, Istituto per la Microelettronica ed i Microsistemi, Via Monteroni I-73100 Lecce, Italy
}

Correspondence should be addressed to Xiangfeng Chu; xfchu99@ahut.edu.cn and Shiming Liang; lsmwind@163.com

Received 23 May 2019; Accepted 30 August 2019; Published 4 December 2019

Academic Editor: Bruno C. Janegitz

Copyright ( 2019 Xiangfeng Chu et al. This is an open access article distributed under the Creative Commons Attribution License, which permits unrestricted use, distribution, and reproduction in any medium, provided the original work is properly cited.

\begin{abstract}
In this paper, $\mathrm{g}-\mathrm{C}_{3} \mathrm{~N}_{4}-\mathrm{WO}_{3}$ composite materials were prepared by hydrothermal processing. The composites were characterized by means of X-ray powder diffraction (XRD), scanning electron microscopy (SEM), Fourier transform infrared spectroscopy (FTIR), $\mathrm{X}$-ray photoelectron spectroscopy (XPS), and $\mathrm{N}_{2}$ adsorption-desorption, respectively. The gas sensing properties of the composites were investigated. The results indicated that the addition of appropriate amount of $g-\mathrm{C}_{3} \mathrm{~N}_{4}$ to $\mathrm{WO}_{3}$ could improve the response and selectivity to acetone. The sensor based on $2 \mathrm{wt} \% \mathrm{~g}-\mathrm{C}_{3} \mathrm{~N}_{4}-\mathrm{WO}_{3}$ composite showed the best gas sensing performances. When operating at optimum temperature of $310^{\circ} \mathrm{C}$, the responses to $1000 \mathrm{ppm}$ and $0.5 \mathrm{ppm}$ acetone were 58.2 and 1.6 , respectively, and the ratio of the $S_{1000 \mathrm{ppm} \text { acetone }}$ to $S_{1000 \mathrm{ppm} \text { ethanol }}$ reached 3.7.
\end{abstract}

\section{Introduction}

Graphitic carbon nitride $\left(\mathrm{g}-\mathrm{C}_{3} \mathrm{~N}_{4}\right)$ nanomaterial exhibits a stable layered structure and $\Pi$-conjugated s-triazine unit composed of $\mathrm{sp}^{2}$ hybridized carbon atoms and $\mathrm{sp}^{2}$ hybridized nitrogen atom. g- $\mathrm{C}_{3} \mathrm{~N}_{4}$ nanosheets have attracted the attention of researchers in recent years for its peculiar properties as a semiconductor such as immense specific surface area [1]. Wang et al. [2] prepared $\mathrm{g}-\mathrm{C}_{3} \mathrm{~N}_{4}$ by thermal treatment of glucose and urea, and the p-type sensor based on g- $\mathrm{C}_{3} \mathrm{~N}_{4}$ exhibited good response to $\mathrm{NO}_{2}$ at room temperature.

As a gas sensing material, $\mathrm{WO}_{3}$ has been paid much attention in the past decade. Cho et al. [3] used ultrasonic spray pyrolysis to prepare $\mathrm{WO}_{3}$ hollow spheres using a citric acid-containing precursor solution; the $\mathrm{WO}_{3}$ hollow spheres exhibited a high response and good gas sensing selectivity to trimethylamine, but the sensor exhibited a depressed response to $\mathrm{NO}_{2}$. Kida et al. [4] used acidification of $\mathrm{Na}_{2} \mathrm{WO}_{4}$ with $\mathrm{H}_{2} \mathrm{SO}_{4}$ solution to prepare lamellar-structured $\mathrm{WO}_{3}$ particles which had a high response $(S=150-280)$ even to dilute $\mathrm{NO}_{2}(50-1000 \mathrm{ppb})$ in air at $200^{\circ} \mathrm{C}$. A study by $\mathrm{Ma}$ et al. [5] showed that $\mathrm{WO}_{3}$ nanoplates obtained through a topochemical transformation of the corresponding $\mathrm{H}_{2} \mathrm{WO}_{4}$ precursor exhibited high response to ethanol while operating at $300^{\circ} \mathrm{C}$.

The photocatalytic activity of g- $\mathrm{C}_{3} \mathrm{~N}_{4}-\mathrm{WO}_{3}$ nanocomposites also has been reported by many researchers [6-9]; the photocatalytic performances of $\mathrm{WO}_{3} / \mathrm{g}-\mathrm{C}_{3} \mathrm{~N}_{4}$ nanocomposites were higher than those of pure $\mathrm{WO}_{3}$ and pure g- $\mathrm{C}_{3} \mathrm{~N}_{4}$, which were attributed to the synergistic effect of $\mathrm{WO}_{3}$ and pure g- $\mathrm{C}_{3} \mathrm{~N}_{4}$. A study by Zhang et al. [10] showed that the ethanol sensing performance of $\alpha-\mathrm{Fe}_{2} \mathrm{O}_{3} / g-\mathrm{C}_{3} \mathrm{~N}_{4}$ nanocomposites was better than that of pure $\alpha-\mathrm{Fe}_{2} \mathrm{O}_{3}$ and g- $\mathrm{C}_{3} \mathrm{~N}_{4}$, which could be caused by porous $\alpha-\mathrm{Fe}_{2} \mathrm{O}_{3}$ nanotubes wrapped by lamellar $\mathrm{g}-\mathrm{C}_{3} \mathrm{~N}_{4}$ nanostructures resulting in the formation of heterojunction. Cao et al. [11] reported that the gas sensing response and selectivity to ethanol could also be enhanced by modification of $\mathrm{g}^{-} \mathrm{C}_{3} \mathrm{~N}_{4}$ nanosheets. The 
combination of $\mathrm{WO}_{3}$ and $\mathrm{g}-\mathrm{C}_{3} \mathrm{~N}_{4}$ may exhibit good gas sensing properties, which to the best of our knowledge has not been reported to date.

In this paper, we report the preparation of $\mathrm{g}-\mathrm{C}_{3} \mathrm{~N}_{4}-\mathrm{WO}_{3}$ nanocomposites through a hydrothermal method and the investigation of their gas sensing properties. Analysis showed that $2 \mathrm{wt} \%$ g- $\mathrm{C}_{3} \mathrm{~N}_{4}-\mathrm{WO}_{3}$ nanocomposite responded highly and selectively to acetone.

\section{Materials and Methods}

2.1. Material Preparation and Characterization. g- $\mathrm{C}_{3} \mathrm{~N}_{4}$ was prepared by heating $2.0 \mathrm{~g}$ melamine in an oven at $520^{\circ} \mathrm{C}$ for 5 hours, while keeping the heating rate at $5^{\circ} \mathrm{C} / \mathrm{min}$, which was similar to that reported in the literature [12]. After cooling to room temperature naturally, the product was purified with ethanol, following which it was dried at $60^{\circ} \mathrm{C}$ for $24 \mathrm{~h}$ succeeded by milling.

For preparing the nanocomposites, a certain amount of as-prepared g- $\mathrm{C}_{3} \mathrm{~N}_{4}$ was added to $40 \mathrm{~mL}$ deionized water and sonicated for 1 hour to obtain a $g-\mathrm{C}_{3} \mathrm{~N}_{4}$ suspension. $0.0025 \mathrm{~mol} \mathrm{Na} 2 \mathrm{WO}_{4} \cdot 2 \mathrm{H}_{2} \mathrm{O}$ was dissolved in $20 \mathrm{~mL}$ deionized water, and $4 \mathrm{~mL}$ concentrated hydrochloric acid was added dropwise in the $\mathrm{Na}_{2} \mathrm{WO}_{4}$ solution slowly while stirring resulting in the formation of $\mathrm{H}_{2} \mathrm{WO}_{4}$; the $\mathrm{g}-\mathrm{C}_{3} \mathrm{~N}_{4}$ suspension was added slowly to $\mathrm{H}_{2} \mathrm{WO}_{4}$ while stirring. The mixture was sealed in a $100 \mathrm{~mL}$ Teflon-lined stainless steel autoclave and heated at $200^{\circ} \mathrm{C}$ for $24 \mathrm{~h}$; the obtained precipitate was filtered and washed with distilled water and ethanol, followed by drying in air at $80^{\circ} \mathrm{C}$ for 24 hours; finally, the $\mathrm{g}-\mathrm{C}_{3} \mathrm{~N}_{4}-\mathrm{WO}_{3}$ composite was obtained. The weight ratios of $\mathrm{g}-\mathrm{C}_{3} \mathrm{~N}_{4}$ powders $/ \mathrm{WO}_{3}$ (the weight of $\mathrm{WO}_{3}$ was calculated according to the weight of $\mathrm{Na}_{2} \mathrm{WO}_{4} \cdot 2 \mathrm{H}_{2} \mathrm{O}$ ) were $0 \mathrm{wt} \%, 1 \mathrm{wt} \%, 2 \mathrm{wt} \%$, $3 \mathrm{wt} \%$, and $4 \mathrm{wt} \%$ (the samples were labeled as S-0, S-1, S-2, S-3, and S-4, respectively).

X-ray diffraction (XRD, Bruker D8 Advance, Cu-K $\alpha$ radiation: $\lambda=0.15418 \mathrm{~nm}$ ), operating at $40 \mathrm{kV}$ and $30 \mathrm{~mA}$ in a $2 \theta$ range from $10^{\circ}$ to $70^{\circ}$ at room temperature, was used to analyze the crystal structure of $\mathrm{g}-\mathrm{C}_{3} \mathrm{~N}_{4}-\mathrm{WO}_{3}$ nanocomposites. A scanning electron microscope (SEM, Hitachi S4800 microscope), with an accelerating voltage of $10 \mathrm{kV}$, was used to characterize the surface morphology of the samples. Fourier transform infrared spectroscopy (FTIR, Nicolet 6700 FTIR Spectrometer) spectra were recorded by the $\mathrm{KBr}$ pellet technique in the range $400-4000 \mathrm{~cm}^{-1}$. The chemical species of elements were analyzed by X-ray photoelectron spectroscopy (XPS, Thermo ESCALAB250Xi) with all of the binding energies corrected according to contaminant carbon $(\mathrm{C} 1 \mathrm{~s}=284.6 \mathrm{eV})$. The specific surface areas were characterized by the Brunauer-Emmett-Teller (BET, ASAP2010C) method using $\mathrm{N}_{2}$ adsorption-desorption measurement.

2.2. Gas Sensing Measurement. The sensor device preparation process and the gas sensing measurement have been explained in the previous work [13]. The gas sensing response of the gas sensor was defined through the ratio of the resistance of the gas sensor in air $\left(R_{\mathrm{a}}\right)$ to that in the test gases $\left(R_{\mathrm{g}}\right)$. Figure $\mathrm{S} 1$, representing the gas sensor, is shown in supplementary materials.

\section{Results and Discussion}

3.1. Characterization. Figure 1 shows the $\mathrm{XRD}$ patterns of pure $\mathrm{g}-\mathrm{C}_{3} \mathrm{~N}_{4}, g-\mathrm{C}_{3} \mathrm{~N}_{4}-\mathrm{WO}_{3}$ (S-1, S-2, S-3, and S-4), and $\mathrm{WO}_{3}$. Two significant diffraction peaks were observed at $13.23^{\circ}$ and $27.86^{\circ}$ in the XRD pattern of $\mathrm{g}-\mathrm{C}_{3} \mathrm{~N}_{4}$, indicating the (100) and (002) planes of layered $\mathrm{g}-\mathrm{C}_{3} \mathrm{~N}_{4}$; the weaker peak at $13.23^{\circ}$ indicates the in-planar tris-s-triazine structural packing, and the stronger peak at $27.86^{\circ}$ corresponds to the stacked of the aromatic systems between layers [6-8, 14]. All the diffraction peaks observed in XRD patterns of S-0, S-1, S-2, S-3, and S-4 could be indexed to the standard data of $\mathrm{WO}_{3}$ (JCPDS 43-1035). The diffraction peaks of $\mathrm{g}-\mathrm{C}_{3} \mathrm{~N}_{4}$ could not be found because of the low concentration of g- $\mathrm{C}_{3} \mathrm{~N}_{4}$ in the composites [14]. It was reported that the diffraction peaks of $g-\mathrm{C}_{3} \mathrm{~N}_{4}$ did not appear in the XRD patterns of $g-\mathrm{C}_{3} \mathrm{~N}_{4}-\mathrm{WO}_{3}$ composites when the content of $\mathrm{WO}_{3}$ was higher than $10 \mathrm{wt} \%$ [15]. The average crystallite sizes were calculated by the Scherrer formula:

$$
D=\frac{K \lambda}{\beta \cos \theta},
$$

where $D$ is the crystallite size, $K$ is the instrument correction factor, $\gamma$ is the $\mathrm{Cu}-\mathrm{K} \alpha$ wavelength $(0.151418 \mathrm{~nm}), \beta$ is the full width at half maximum of the peaks, and $\theta$ is the position of the peaks. The average crystallite sizes of $\mathrm{WO}_{3}$ in S-0, S-1, S-2, S-3, and S-4 were 54.9, 62.6, 44.4, 44.3, and $50.2 \mathrm{~nm}$, respectively. The calculated particle size of $\mathrm{g}-\mathrm{C}_{3} \mathrm{~N}_{4}$ was about $5.7 \mathrm{~nm}$.

Figure 2 exhibits the SEM images of $\mathrm{g}-\mathrm{C}_{3} \mathrm{~N}_{4}$, pure $\mathrm{WO}_{3}$ $(\mathrm{S}-0)$, and $\mathrm{g}-\mathrm{C}_{3} \mathrm{~N}_{4}-\mathrm{WO}_{3}(\mathrm{~S}-2)$. The morphology of $\mathrm{g}-\mathrm{C}_{3} \mathrm{~N}_{4}$ was a sheet that consisted of small particles, and the particle sizes were about $200 \mathrm{~nm}$. The $\mathrm{WO}_{3}$ particle sizes in $\mathrm{WO}_{3}$ and g- $\mathrm{C}_{3} \mathrm{~N}_{4}-\mathrm{WO}_{3}$ were between 100 and $400 \mathrm{~nm}$; the addition of g- $\mathrm{C}_{3} \mathrm{~N}_{4}$ in the composite had no obvious influence on the particle size of $\mathrm{WO}_{3}$. The particle sizes obtained from SEM images were larger than those calculated from the Scherrer formula, which manifested that the particles observed by SEM in $g-\mathrm{C}_{3} \mathrm{~N}_{4}$, pure $\mathrm{WO}_{3}$, and $\mathrm{g}-\mathrm{C}_{3} \mathrm{~N}_{4}-\mathrm{WO}_{3}$ were aggregates of smaller particles.

The FTIR spectra of $\mathrm{WO}_{3}$ and $\mathrm{g}-\mathrm{C}_{3} \mathrm{~N}_{4}-\mathrm{WO}_{3}(\mathrm{~S}-2)$ are shown in Figure 3. The absorption peaks at 763, 822, and $935 \mathrm{~cm}^{-1}$ in the spectra of two samples originated from stretching vibrations of $\mathrm{O}-\mathrm{W}-\mathrm{O}$ in $\mathrm{WO}_{3}[9,15,16]$; the peaks at 1632 and $3436 \mathrm{~cm}^{-1}$ in the FTIR spectra of $\mathrm{WO}_{3}$ and g- $\mathrm{C}_{3} \mathrm{~N}_{4}-\mathrm{WO}_{3}$ (S-2) resulted from the vibration of bended $\mathrm{H}-\mathrm{O}-\mathrm{H}$ and stretched $\mathrm{O}-\mathrm{H}$ of absorbed $\mathrm{H}_{2} \mathrm{O}$ on the material surface [17]; and absorption peaks in the FTIR spectrum of $\mathrm{g}$ $\mathrm{C}_{3} \mathrm{~N}_{4}-\mathrm{WO}_{3}$ (S-2), other than those of $\mathrm{WO}_{3}$, at 1244,1321 , 1411,1567 , and $1632 \mathrm{~cm}^{-1}$ were ascribed to stretching vibration of C-NH-C and $\mathrm{C}=\mathrm{N}$ of heterocycles [15], which proved the existence of $\mathrm{g}-\mathrm{C}_{3} \mathrm{~N}_{4}$ in the composite. The XPS results were discussed in the supplementary materials, which could prove the formation of $\mathrm{g}-\mathrm{C}_{3} \mathrm{~N}_{4}-\mathrm{WO}_{3}$.

3.2. Gas Sensing Characterization. The gas sensing responses of pure $\mathrm{WO}_{3}, \mathrm{~S}-1, \mathrm{~S}-2, \mathrm{~S}-3$, and S-4 to 1000 ppm concentration of acetone at different operating temperatures are shown 


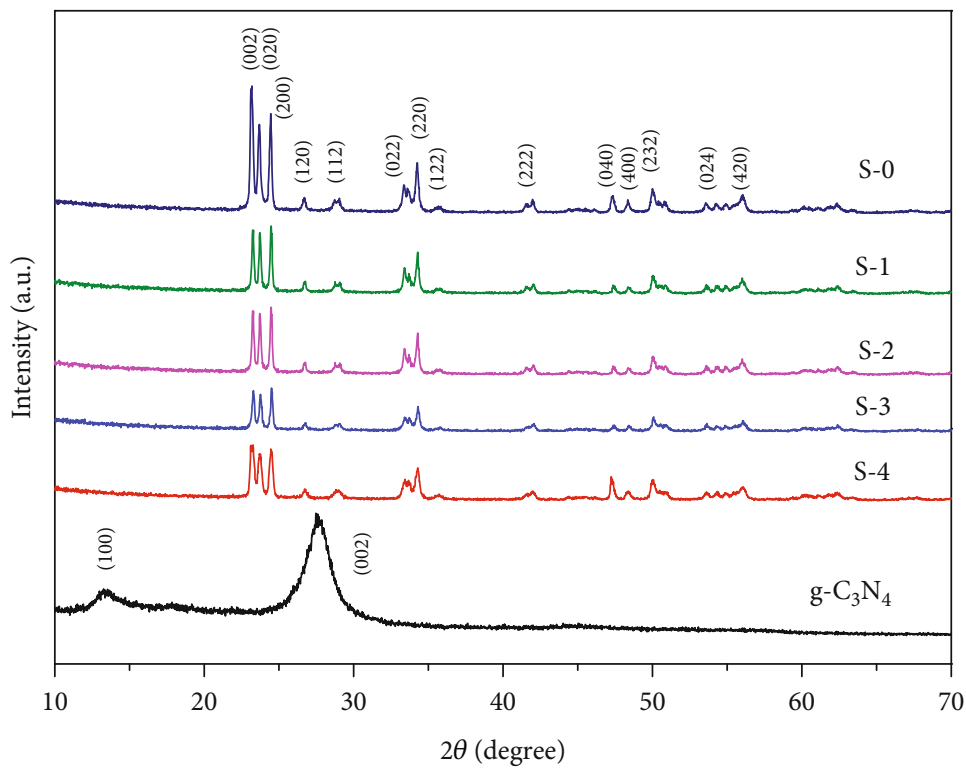

Figure 1: The XRD patterns of pure $\mathrm{g}_{3} \mathrm{C}_{3} \mathrm{~N}_{4}, \mathrm{~g}-\mathrm{C}_{3} \mathrm{~N}_{4}-\mathrm{WO}_{3}\left(\mathrm{~S}-1, \mathrm{~S}-2, \mathrm{~S}-3\right.$, and S-4), and $\mathrm{WO}_{3}$.

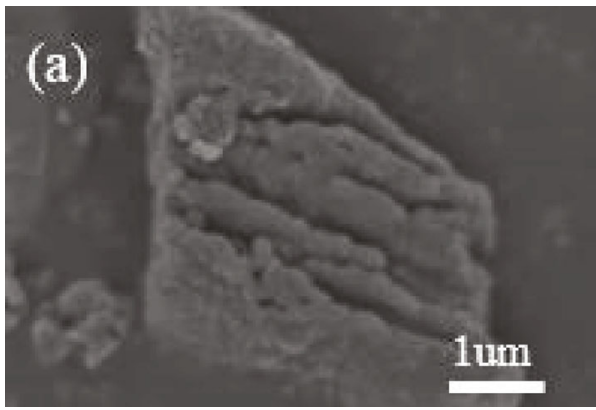

(a)

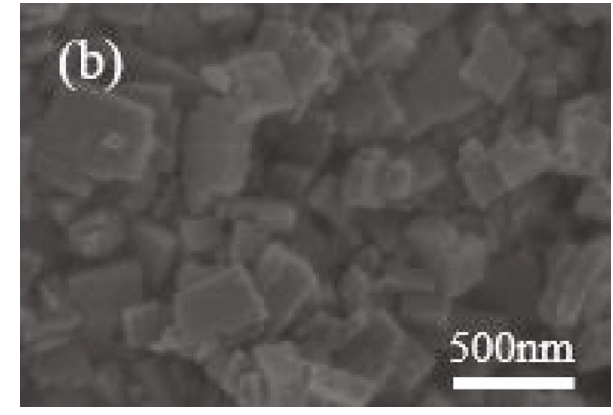

(b)

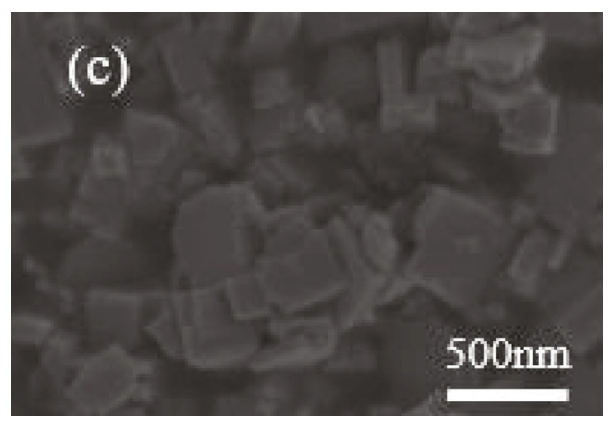

(c)

Figure 2: The SEM images of (a) $g-\mathrm{C}_{3} \mathrm{~N}_{4}$, (b) pure $\mathrm{WO}_{3}(\mathrm{~S}-0)$, and (c) $\mathrm{g}-\mathrm{C}_{3} \mathrm{~N}_{4}-\mathrm{WO}_{3}(\mathrm{~S}-2)$.

in Figure 4. An increase in the response with an increase in the amount of $\mathrm{g}-\mathrm{C}_{3} \mathrm{~N}_{4}$ in the $\mathrm{g}-\mathrm{C}_{3} \mathrm{~N}_{4}-\mathrm{WO}_{3}$ composite was observed while the content of $\mathrm{g}_{-} \mathrm{C}_{3} \mathrm{~N}_{4}$ was lower than $2 \mathrm{wt} \%$; when the contents of $\mathrm{g}-\mathrm{C}_{3} \mathrm{~N}_{4}$ in the $\mathrm{g}-\mathrm{C}_{3} \mathrm{~N}_{4}-\mathrm{WO}_{3}$ composite were $3 \mathrm{wt} \%$ and $4 \mathrm{wt} \%$, the responses decreased significantly; the optimal operating temperatures for S-1 and S-2 were all $310^{\circ} \mathrm{C}$, which were better than that for pure $\mathrm{WO}_{3}$. The responses of pure $\mathrm{WO}_{3}, \mathrm{~S}-1, \mathrm{~S}-2, \mathrm{~S}-3$, and S-4 to $1000 \mathrm{ppm}$ acetone at $310^{\circ} \mathrm{C}$ were $3.7,16.2,58.2,1.0$, and 1.3 , respectively. It has been reported that pure g- $\mathrm{C}_{3} \mathrm{~N}_{4}$ exhibited very little response to acetone; the response improved significantly for a particular content of g- $\mathrm{C}_{3} \mathrm{~N}_{4}$ in a series of $\mathrm{g}-\mathrm{C}_{3} \mathrm{~N}_{4}-\mathrm{SnO}_{2}$ nanocomposites [18]. The response of $\alpha-\mathrm{Fe}_{2} \mathrm{O}_{3} / \mathrm{g}-\mathrm{C}_{3} \mathrm{~N}_{4}$ to ethanol was also reported [11]; an appropriate amount of $\mathrm{g}_{-} \mathrm{C}_{3} \mathrm{~N}_{4}$ in the composites was propitious to the dispersion of $\alpha-\mathrm{Fe}_{2} \mathrm{O}_{3}$ in the composites and the formation of better heterojunctions; the reasons for the enhancement of gas sensing response were attributed to the larger specific surface area, better permeability, and heterojunction. A sensor based on the S-2 composite 


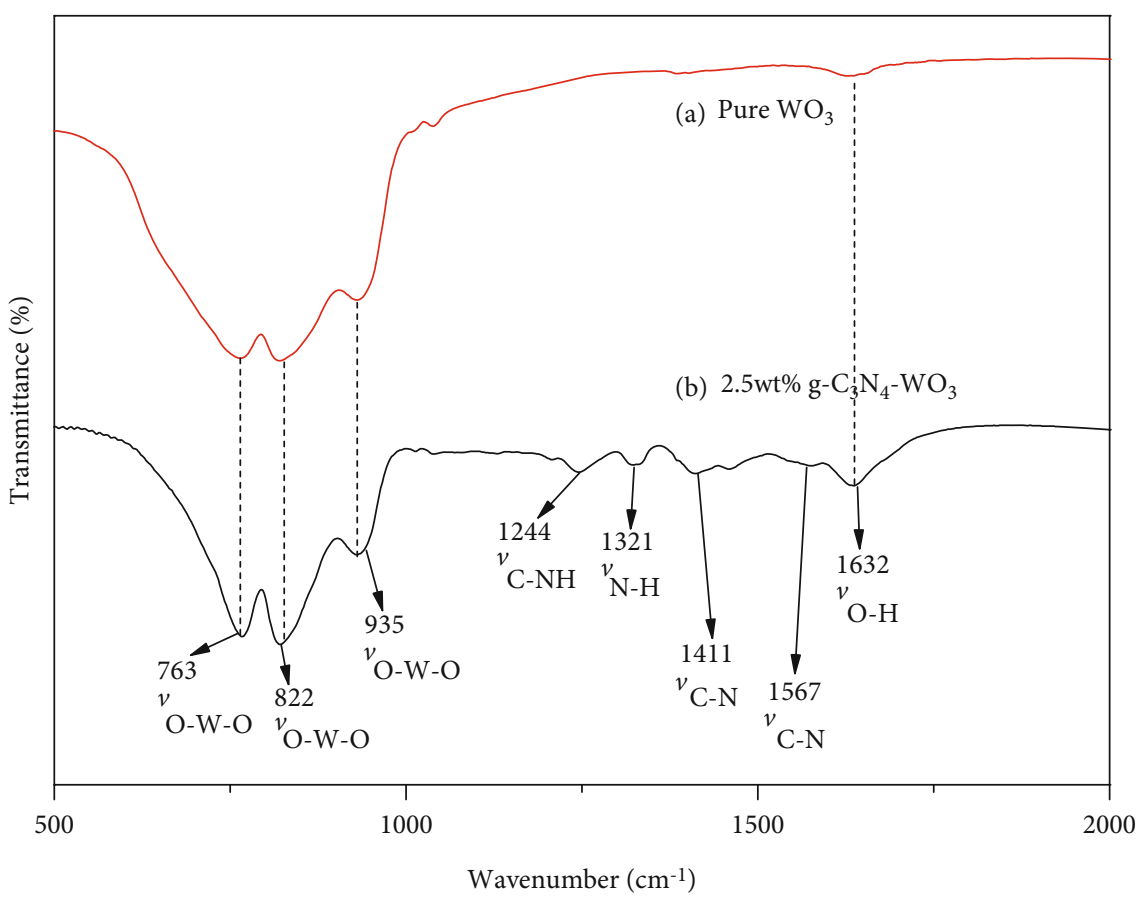

Figure 3: The FTIR spectra of $\mathrm{WO}_{3}$ and $g-\mathrm{C}_{3} \mathrm{~N}_{4}-\mathrm{WO}_{3}(\mathrm{~S}-2)$.

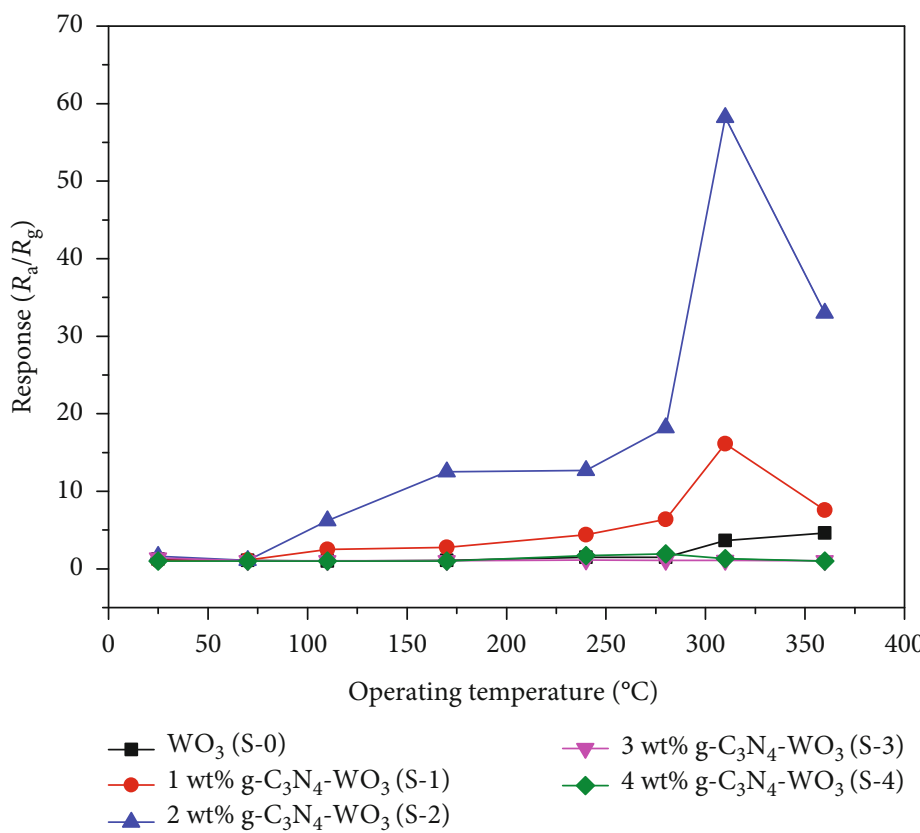

Figure 4: The gas sensing responses of pure $\mathrm{WO}_{3}, \mathrm{~S}-1, \mathrm{~S}-2, \mathrm{~S}-3$, and S-4 to $1000 \mathrm{ppm}$ acetone at different temperatures.

exhibited higher response to acetone compared with pure $\mathrm{WO}_{3}$. The $\mathrm{N}_{2}$ adsorption-desorption results are shown in Figure S3 of supplementary materials; the average pore size difference between S-0 and S-2 was not obvious, and the gas diffusion rates in the inner sections of S-0 and S-2 were approximate; the enhancement of gas sensing response of S-2 was probably attributable to the larger specific surface area of S-2 and heterojunction. Many literatures have reported the acetone sensing mechanism of $\mathrm{WO}_{3}[19,20]$, and the conductance of the $\mathrm{WO}_{3}$ sensor is influenced by the changes in chemisorbed oxygen present on the surface of the gas sensing material; on exposure of a sensor to air, oxygen is adsorbed on the surface of $\mathrm{WO}_{3}$, which in turn captured electrons from the conduction band of $\mathrm{WO}_{3}$, resulting in the decrease in electron concentration in the conduction band; oxygen molecules

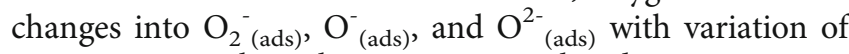
temperature. When the sensor was placed in an acetone 


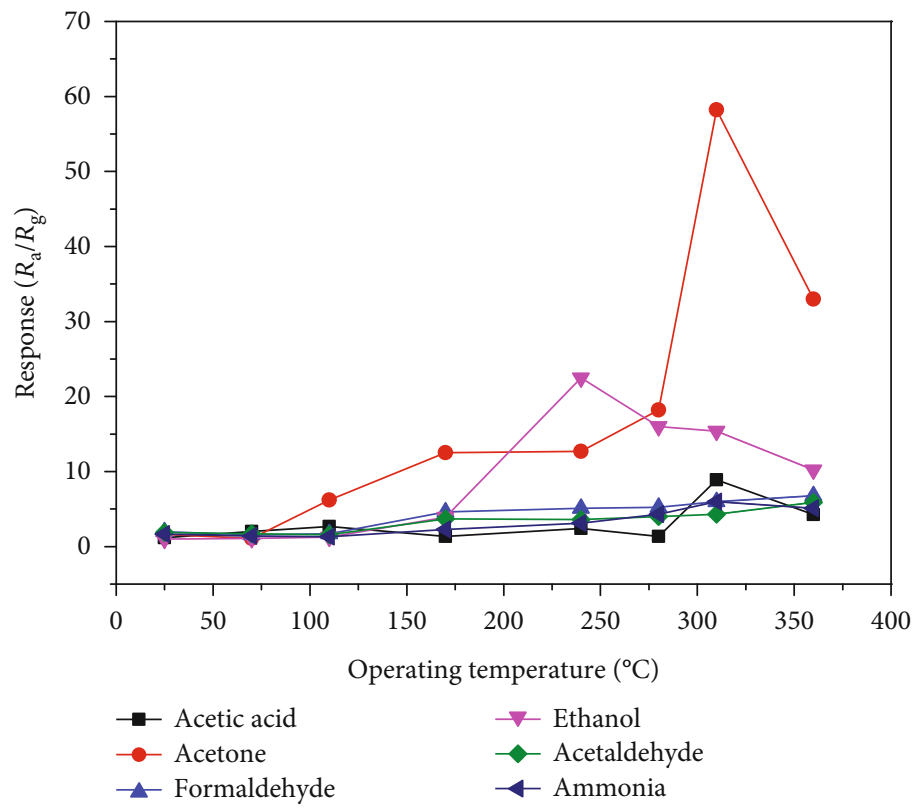

Figure 5: The responses of an S-2-based sensor to $1000 \mathrm{ppm}$ acetic acid, acetone, formaldehyde, ethanol, acetaldehyde, and ammonia at different operating temperatures.

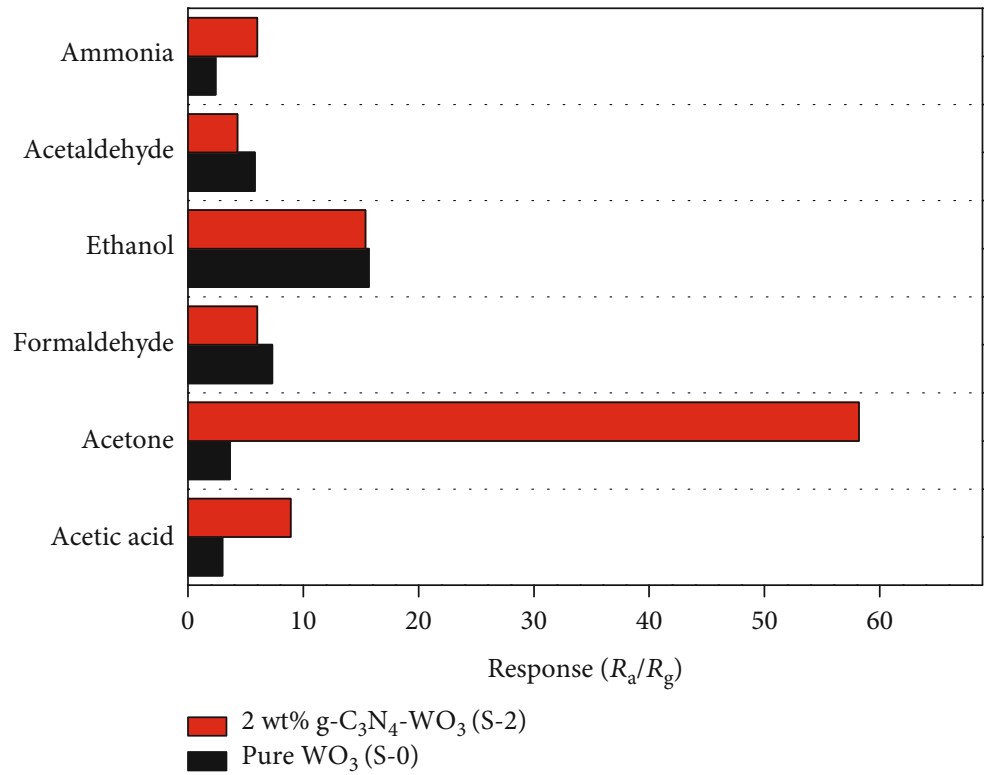

Figure 6: The responses of sensors based on S-0 and S-2 to six kinds of gases $(1000 \mathrm{ppm})$ at $310^{\circ} \mathrm{C}$.

vapor atmosphere, acetone reacted with $\mathrm{O}_{2}^{-}\left(\right.$ads) $\mathrm{O}^{-}{ }_{(\text {ads) }}$, and $\mathrm{O}^{2-}$ (ads), releasing the electrons captured by oxygen molecules to the conduction band of $\mathrm{WO}_{3}$ and decreasing the resistance of the sensor. The reaction is as follows:

$$
\mathrm{CH}_{3} \mathrm{COCH}_{3}+4 \mathrm{O}_{2^{-}}(\mathrm{ads})=3 \mathrm{CO}_{2}+3 \mathrm{H}_{2} \mathrm{O}+4 e
$$

Figure 5 depicts the responses of an S-2-based sensor to $1000 \mathrm{ppm}$ acetic acid, acetone, formaldehyde, ethanol, acetaldehyde, and ammonia at different temperatures. The optimal operating temperatures for formaldehyde, ethanol, and acetaldehyde were $360^{\circ} \mathrm{C}, 240^{\circ} \mathrm{C}$, and $360^{\circ} \mathrm{C}$, respectively; the maximum responses for acetic acid, acetone, and ammonia all appeared at $310^{\circ} \mathrm{C}$. At an operating temperature of $310^{\circ} \mathrm{C}$, the responses to $1000 \mathrm{ppm}$ acetic acid, acetone, formaldehyde, ethanol, acetaldehyde, and ammonia were $8.9,58.2,6.0,15.4,4.3$, and 6.0, respectively; the S-2 sensor showed significant gas sensing selectivity to acetone, with the response ratio of $S_{1000} \mathrm{ppm}$ acetone $/ S_{1000} \mathrm{ppm}$ ethanol reaching 3.8.

Figure 6 shows the responses of S-0- and S-2-based sensors to six kinds of gases, while keeping the concentration 


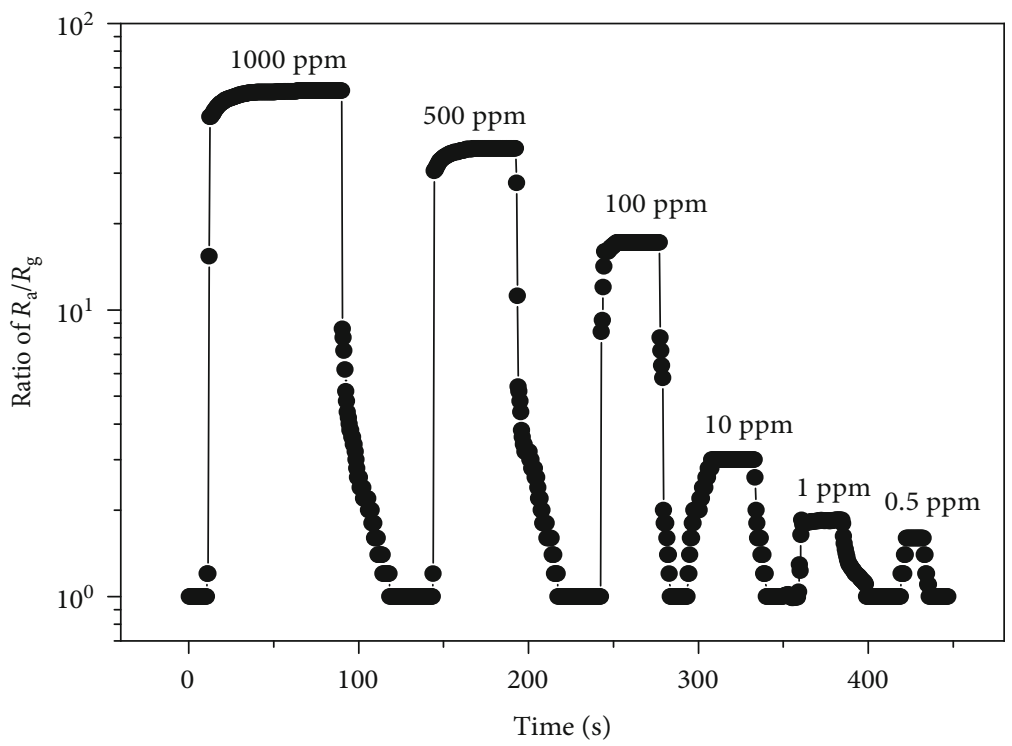

FIGURE 7: The response transients of the sensor based on the sample S-2 composite to acetone (1000 ppm, $500 \mathrm{ppm}, 100 \mathrm{ppm}, 10 \mathrm{ppm}, 1 \mathrm{ppm}$, and $0.5 \mathrm{ppm})$ at $310^{\circ} \mathrm{C}$.

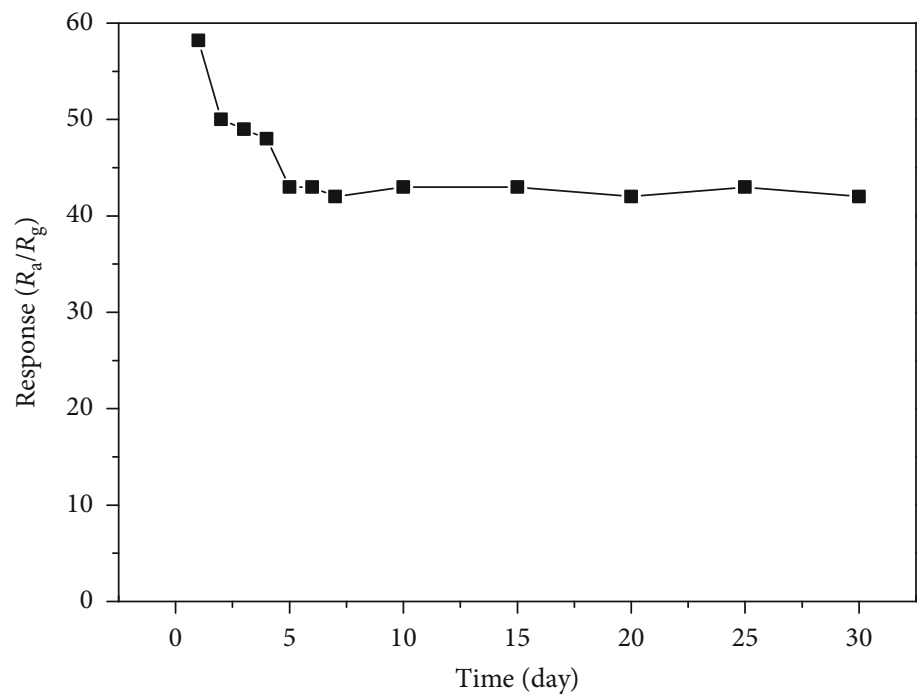

Figure 8: The curve of gas sensing response versus time of the S-2 sensor.

$1000 \mathrm{ppm}$, at $310^{\circ} \mathrm{C}$. The responses of the S-2 sensor to acetaldehyde, ethanol, and formaldehyde were lower than those of the pure $\mathrm{WO}_{3}$ sensor. But the responses of the S-2 sensor to ammonia, acetone, and acetic acid were higher than those of the pure $\mathrm{WO}_{3}$ gas sensor; especially, the response of the S2 sensor to acetone was 15 times that of the pure $\mathrm{WO}_{3}$ gas sensor, proving the role of $\mathrm{g}-\mathrm{C}_{3} \mathrm{~N}_{4}$ in improving the selectivity of the gas sensor.

The response time and recovery time were calculated using the formula defined in a previous literature [21]. The response curve transients of the sensor based on the sample $\mathrm{S}-2$ composite to acetone $(1000 \mathrm{ppm}, 500 \mathrm{ppm}, 100 \mathrm{ppm}$, $10 \mathrm{ppm}, 1 \mathrm{ppm}$, and $0.5 \mathrm{ppm})$ at $310^{\circ} \mathrm{C}$ are shown in Figure 7. The responses to $1000 \mathrm{ppm}, 500 \mathrm{ppm}, 100 \mathrm{ppm}$, $10 \mathrm{ppm}, 1 \mathrm{ppm}$, and $0.5 \mathrm{ppm}$ acetone were $58.2,36.6,17.2$, $3.0,1.8$, and 1.6, respectively; the detection limit of the
S-2 composite-based sensor to acetone was $0.5 \mathrm{ppm}$. The response times for $1000,500,100,10,1$, and $0.5 \mathrm{ppm}$ acetone were $53,24,10,15,7$, and $5 \mathrm{~s}$, respectively, while the recovery times for $1000,500,100,10,1$, and $0.5 \mathrm{ppm}$ acetone were 29 , $25,6,7,12$, and $3 \mathrm{~s}$, respectively. The acetone concentration in the breath varies from 0.3 to $0.9 \mathrm{ppm}$ for healthy people, but the acetone concentration exceeds $1.8 \mathrm{ppm}$ for diabetic patients [22]. The S-2 composite-based sensor had a response of 1.6 to $0.5 \mathrm{ppm}$ acetone which meant that it has the potential for application in diabetes detection.

The gas sensor stability is a significant parameter for a gas sensor, and the curve of gas sensing response versus time of the S-2 composite-based sensor is shown in Figure 8. The gas sensing response decreased significantly in seven days and then achieved stability between the seventh and thirtieth days. The stability of the sensor can be improved further. The 
TABLE 1: Comparison of acetone gas sensing properties with different acetone gas sensors.

\begin{tabular}{|c|c|c|c|c|c|c|}
\hline Material & $\begin{array}{c}\text { Operating } \\
\text { temperature }\left({ }^{\circ} \mathrm{C}\right)\end{array}$ & $\begin{array}{l}\text { Detection } \\
\text { limit }(\mathrm{ppm})\end{array}$ & $\begin{array}{c}\text { Response }\left(R_{\mathrm{a}} / R_{\mathrm{g}}\right) \\
\text { (concentration) }\end{array}$ & Selectivity & Stability (days) & Reference \\
\hline $\mathrm{Au} / \mathrm{ZnO}$ & 365 & 20 & $2923(100 \mathrm{ppm})$ & 1.8 & 90 & [23] \\
\hline $\mathrm{MgFe}_{2-x} \mathrm{Ce}_{x} \mathrm{O}_{4}$ & 700 & 100 & $1.91(2000 \mathrm{ppm})$ & 1.2 & - & [24] \\
\hline $\mathrm{Co}_{3} \mathrm{O}_{4}$ NWS-HCSs & 150 & 1 & $23(200 \mathrm{ppm})$ & 4.6 & - & {$[25]$} \\
\hline $\mathrm{PrFeO}_{3}$ & 180 & 10 & $141(200 \mathrm{ppm})$ & 2.8 & 75 & {$[26]$} \\
\hline $\mathrm{Pt}-\mathrm{Fe}_{2} \mathrm{O}_{3}$ & 139 & 0.2 & 25.7 (100 ppm) & 2.9 & 15 & {$[27]$} \\
\hline Rh- doped $\mathrm{SnO}_{2}$ & 200 & 1 & $60.6(50 \mathrm{ppm})$ & 8.6 & - & {$[28]$} \\
\hline $\mathrm{ZnFe}_{2} \mathrm{O}_{4}$ & 260 & 10 & $52.8(100 \mathrm{ppm})$ & 3.2 & 30 & [29] \\
\hline $\mathrm{g}-\mathrm{C}_{3} \mathrm{~N}_{4}-\mathrm{WO}_{3}$ & 310 & 0.5 & $58.2(1000 \mathrm{ppm})$ & 3.7 & 30 & This work \\
\hline
\end{tabular}

“-” means no data available in the literature.

g- $\mathrm{C}_{3} \mathrm{~N}_{4}-\mathrm{WO}_{3}$ composite (S-2) has proven itself to be a potential candidate for application as an acetone sensor, if the stability of the sensor can be improved.

Table 1 compares the gas sensing properties of different acetone sensors. Overall, the g- $\mathrm{C}_{3} \mathrm{~N}_{4}-\mathrm{WO}_{3}$ acetone gas sensor showed good sensitivity to acetone and also had significant selectivity. Besides, the detection limit is as low as $0.5 \mathrm{ppm}$ which is the second lowest in the listed acetone sensor.

\section{Conclusions}

It can be observed that the content of $\mathrm{g}-\mathrm{C}_{3} \mathrm{~N}_{4}$ in $\mathrm{g}-\mathrm{C}_{3} \mathrm{~N}_{4}$ $\mathrm{WO}_{3}$ composites influences the response and selectivity of g- $\mathrm{C}_{3} \mathrm{~N}_{4}-\mathrm{WO}_{3}$ composite-based sensors to acetone. $2 \mathrm{wt} \%$ g- $\mathrm{C}_{3} \mathrm{~N}_{4}-\mathrm{WO}_{3}$ composite ( $\left.\mathrm{S}-2\right)$ showed the best gas sensing performances in the series of $\mathrm{g}-\mathrm{C}_{3} \mathrm{~N}_{4}-\mathrm{WO}_{3}$ composites, when operating at an optimum temperature of $310^{\circ} \mathrm{C}$; the responses to $1000 \mathrm{ppm}$ and $0.5 \mathrm{ppm}$ acetone were 58.2 and 1.6 , respectively, with the ratio of the $S_{1000 \mathrm{ppm}}$ acetone to $S_{1000 \mathrm{ppm} \text { ethanol }}$ reaching 3.7; the S-2 composite-based sensor was able to detect acetone at concentrations as low as $0.5 \mathrm{ppm}$. The sensor took $5 \mathrm{~s}$ and $3 \mathrm{~s}$ to respond to $0.5 \mathrm{ppm}$ acetone and to recover; the $\mathrm{g}-\mathrm{C}_{3} \mathrm{~N}_{4}-\mathrm{WO}_{3}$ composite (S-2) has proven to be a potential candidate for application as an acetone sensor if the stability of the sensor can be improved.

\section{Data Availability}

The underlying data related to this manuscript is available on request.

\section{Conflicts of Interest}

The authors declare no conflict of interest.

\section{Acknowledgments}

This research was funded by the National Natural Science Foundation of China (Nos. 61671019 and 61971003).

\section{Supplementary Materials}

Figure S1: gas sensor used for characterizing gas sensing

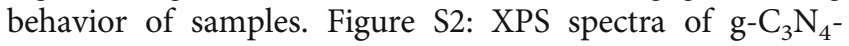
$\mathrm{WO}_{3}$ (S-2): (a) full spectrum. (b) C1s. (c) N1s. (d) O1s. (e)
W. Figure S3: (a) $\mathrm{N}_{2}$ adsorption-desorption isotherm of $\mathrm{WO}_{3}$. (b) Pore size distribution curve of $\mathrm{WO}_{3}$. (c) $\mathrm{N}_{2}$ adsorption-desorption isotherm of $\mathrm{g}-\mathrm{C}_{3} \mathrm{~N}_{4}-\mathrm{WO}_{3}$ (S-2). (d)

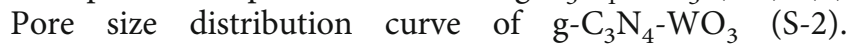
(Supplementary Materials)

\section{References}

[1] L. Yang, X. Liu, Z. Liu et al., "Enhanced photocatalytic activity of $\mathrm{g}-\mathrm{C}_{3} \mathrm{~N}_{4} 2 \mathrm{D}$ nanosheets through thermal exfoliation using dicyandiamide as precursor," Ceramics International, vol. 44, no. 17, pp. 20613-20619, 2018.

[2] D. Wang, W. Gu, Y. Zhang et al., "Novel C-rich carbon nitride for room temperature $\mathrm{NO}_{2}$ gas sensors," RSC Advances, vol. 4, no. 35, pp. 18003-18006, 2014.

[3] Y. H. Cho, Y. C. Kang, and J. H. Lee, "Highly selective and sensitive detection of trimethylamine using $\mathrm{WO}_{3}$ hollow spheres prepared by ultrasonic spray pyrolysis," Sensors and Actuators B: Chemical, vol. 176, pp. 971-977, 2013.

[4] T. Kida, A. Nishiyama, M. Yuasa, K. Shimanoe, and N. Yamazoe, "Highly sensitive $\mathrm{NO}_{2}$ sensors using lamellarstructured $\mathrm{WO}_{3}$ particles prepared by an acidification method," Sensors and Actuators B: Chemical, vol. 135, no. 2, pp. 568-574, 2009.

[5] J. Ma, J. Zhang, S. Wang et al., "Topochemical preparation of $\mathrm{WO}_{3}$ nanoplates through precursor $\mathrm{H}_{2} \mathrm{WO}_{4}$ and their gassensing performances," The Journal of Physical Chemistry C, vol. 115, no. 37, pp. 18157-18163, 2011.

[6] K. Katsumata, R. Motoyoshi, N. Matsushita, and K. Okada, "Preparation of graphitic carbon nitride $\left(\mathrm{g}-\mathrm{C}_{3} \mathrm{~N}_{4}\right) / \mathrm{WO}_{3}$ composites and enhanced visible-light-driven photodegradation of acetaldehyde gas," Journal Hazardous Materials, vol. 260, pp. 475-482, 2013.

[7] Z. Jin, N. Murakami, T. Tsubota, and T. Ohno, "Complete oxidation of acetaldehyde over a composite photocatalyst of graphitic carbon nitride and tungsten(VI) oxide under visible-light irradiation," Applied Catalysis B: Environmental, vol. 150-151, pp. 479-485, 2014.

[8] H. Katsumata, Y. Tachi, T. Suzuki, and S. Kaneco, "Z-scheme photocatalytic hydrogen production over $\mathrm{WO}_{3} / \mathrm{g}-\mathrm{C}_{3} \mathrm{~N}_{4}$ composite photocatalysts," RSC Advances, vol. 4, no. 41, pp. 21405-21409, 2014.

[9] M. Karimi-Nazarabad and E. K. Goharshadi, "Highly efficient photocatalytic and photoelectrocatalytic activity of solar light driven $\mathrm{WO}_{3} / \mathrm{g}-\mathrm{C}_{3} \mathrm{~N}_{4}$ nanocomposite," Solar Energy Materials \& Solar Cells, vol. 160, pp. 484-493, 2017. 
[10] Y. Zhang, D. Zhang, W. Guo, and S. Chen, "The $\alpha-\mathrm{Fe}_{2} \mathrm{O}_{3} / \mathrm{g}-$ $\mathrm{C}_{3} \mathrm{~N}_{4}$ heterostructural nanocomposites with enhanced ethanol gas sensing performance," Journal of Alloys and Compounds, vol. 685, pp. 84-90, 2016.

[11] J. Cao, C. Qin, Y. Wang et al., "Synthesis of g- $\mathrm{C}_{3} \mathrm{~N}_{4}$ nanosheet modified $\mathrm{SnO}_{2}$ composites with improved performance for ethanol gas sensing," RSC Advances, vol. 7, no. 41, pp. 25504-25511, 2017.

[12] X. Wang, K. Maeda, A. Thomas et al., "A metal-free polymeric photocatalyst for hydrogen production from water under visible light," Nature Materials, vol. 8, no. 1, pp. 76-80, 2009.

[13] X. Chu, J. Wang, L. Bai, Y. Dong, W. Sun, and W. Zhang, "Trimethylamine and ethanol sensing properties of $\mathrm{NiGa}_{2} \mathrm{O}_{4}$ nano-materials prepared by co-precipitation method," Sensors and Actuators B: Chemical, vol. 255, pp. 2058-2065, 2018.

[14] F. Zhan, R. Xie, W. Li et al., "In situ synthesis of g- $\mathrm{C}_{3} \mathrm{~N}_{4} / \mathrm{WO}_{3}$ heterojunction plates array films with enhanced photoelectrochemical performance," RSC Advances, vol. 5, no. 85, pp. 69753-69760, 2015.

[15] J. Ding, Q. Liu, Z. Zhang et al., "Carbon nitride nanosheets decorated with $\mathrm{WO}_{3}$ nanorods: ultrasonic-assisted facile synthesis and catalytic application in the green manufacture of dialdehydes," Applied Catalysis B: Environmental, vol. 165, pp. 511-518, 2015.

[16] H. Xu, L. Liu, X. She et al., " $\mathrm{WO}_{3}$ nanorod photocatalysts decorated with few-layer g- $\mathrm{C}_{3} \mathrm{~N}_{4}$ nanosheets: controllable synthesis and photocatalytic mechanism research," RSC Advances, vol. 6, no. 83, pp. 80193-80200, 2016.

[17] S. P. Adhikari, H. R. Pant, H. J. Kim, C. H. Park, and C. S. Kim, "Deposition of $\mathrm{ZnO}$ flowers on the surface of $\mathrm{g}-\mathrm{C}_{3} \mathrm{~N}_{4}$ sheets via hydrothermal process," Ceramics International, vol. 41, no. 10, pp. 12923-12929, 2015.

[18] J. Hu, C. Zou, Y. Su et al., "One-step synthesis of $2 \mathrm{D} \mathrm{C}_{3} \mathrm{~N}_{4}$-tin oxide gas sensors for enhanced acetone vapor detection," Sensors and Actuators B: Chemical, vol. 253, pp. 641-651, 2017.

[19] D. Chen, X. Hou, T. Li et al., "Effects of morphologies on acetonesensing properties of tungsten trioxide nanocrystals," Sensors and Actuators B: Chemical, vol. 153, no. 2, pp. 373-381, 2017.

[20] J. Kaur, K. Anand, A. Kaur, and R. C. Singh, "Sensitive and selective acetone sensor based on $\mathrm{Gd}$ doped $\mathrm{WO}_{3}$ /reduced graphene oxide nanocomposite," Sensors and Actuators B: Chemical, vol. 258, pp. 1022-1035, 2018.

[21] X. Chu, P. Dai, S. Liang, A. Bhattacharya, Y. Dong, and M. Epifani, "The acetone sensing properties of $\mathrm{ZnFe} 2 \mathrm{O} 4$ graphene quantum dots (GQDs) nanocomposites at room temperature," Physica E: Low-dimensional Systems and Nanostructures, vol. 106, pp. 326-333, 2019.

[22] S. K. Rai, K. W. Kao, S. Gwo, A. Agarwal, W. D. Lin, and J. A. Yeh, "Indium nitrite (InN)-based ultrasensitive and selective ammonia sensor using an external silicone oil filter for medical application," Sensors, vol. 18, no. 11, p. 3887, 2018.

[23] P. Wang, T. Dong, C. Jia, and P. Yang, "Ultraselective acetone-gas sensor based $\mathrm{ZnO}$ flowers functionalized by $\mathrm{Au}$ nanoparticle loading on certain facet," Sensors and Actuators B: Chemical, vol. 288, pp. 1-11, 2019.

[24] J. Y. Patil, D. Y. Nadargi, I. S. Mulla, and S. S. Suryavanshi, "Cerium doped $\mathrm{MgFe}_{2} \mathrm{O}_{4}$ nanocomposites: highly sensitive and fast response-recoverable acetone gas sensor," Heliyon, vol. 5, no. 6, article e01489, 2019.

[25] C. Zhang, L. Li, L. Hou, and W. Chen, "Fabrication of $\mathrm{Co}_{3} \mathrm{O}_{4}$ nanowires assembled on the surface of hollow carbon spheres for acetone gas sensing," Sensors and Actuators B: Chemical, vol. 291, pp. 130-140, 2019.

[26] L. Ma, S. Y. Ma, X. F. Shen et al., " $\mathrm{PrFeO}_{3}$ hollow nanofibers as a highly efficient gas sensor for acetone detection," Sensors and Actuators B: Chemical, vol. 255, pp. 2546-2554, 2018.

[27] S. Zhang, M. Yang, K. Liang et al., "An acetone gas sensor based on nanosized Pt-loaded $\mathrm{Fe}_{2} \mathrm{O}_{3}$ nanocubes," Sensors and Actuators B: Chemical, vol. 290, pp. 59-67, 2019.

[28] X. Kou, N. Xie, F. Chen et al., "Superior acetone gas sensor based on electrospun $\mathrm{SnO}_{2}$ nanofibers by Rh doping," Sensors and Actuators B: Chemical, vol. 256, pp. 861-869, 2018.

[29] L. Li, J. Tan, M. Dun, and X. Huang, "Porous $\mathrm{ZnFe}_{2} \mathrm{O}_{4}$ nanorods with net-worked nanostructure for highly sensor response and fast response acetone gas sensor," Sensors and Actuators B: Chemical, vol. 248, pp. 85-91, 2017. 


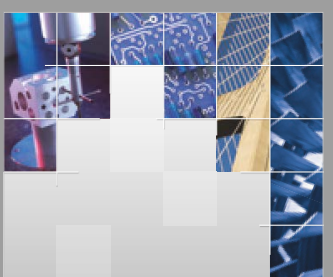

\section{Enfincering}
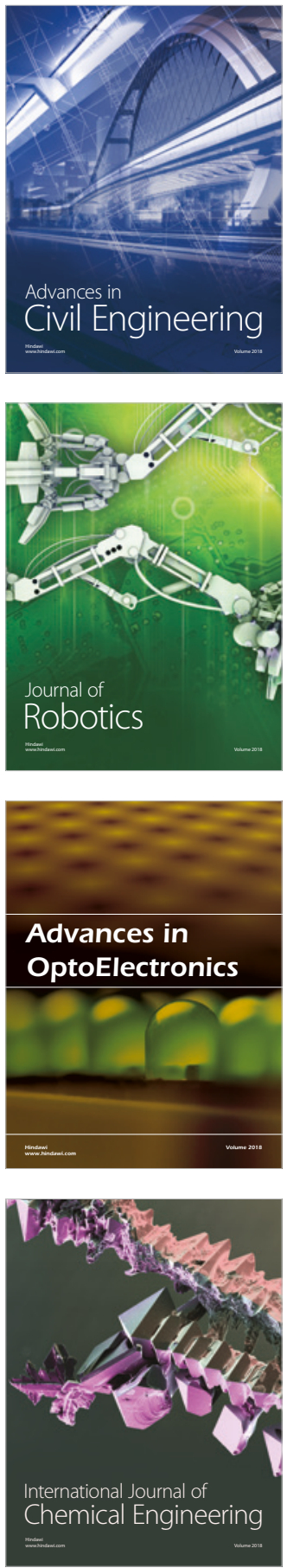

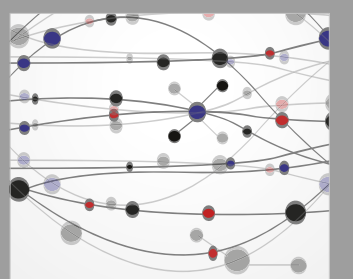

\section{Rotating \\ Machinery}

The Scientific World Journal

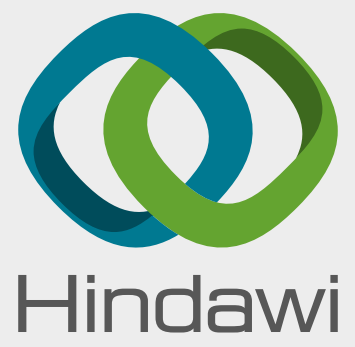

Submit your manuscripts at

www.hindawi.com
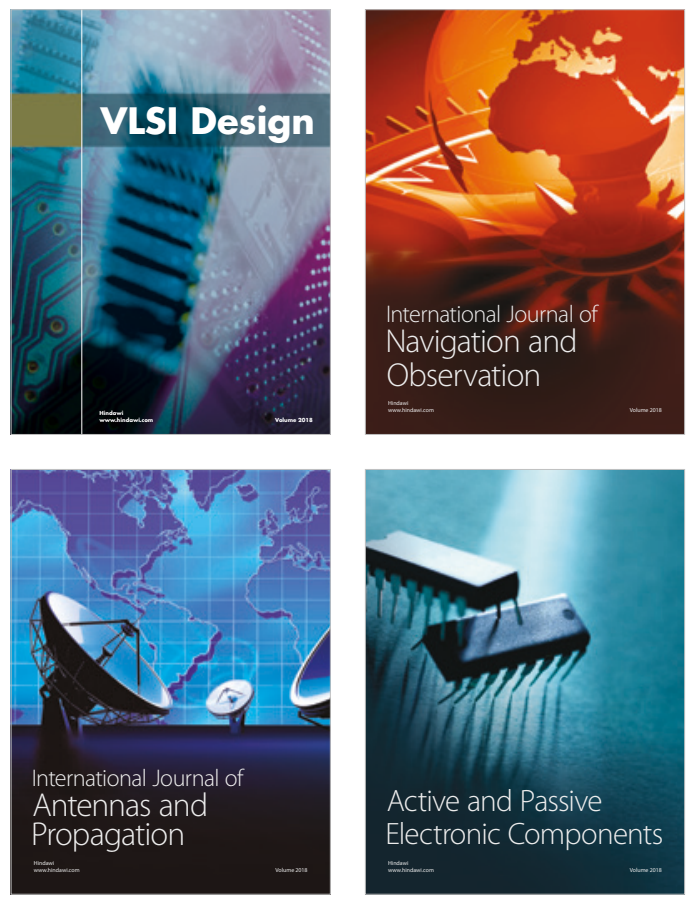
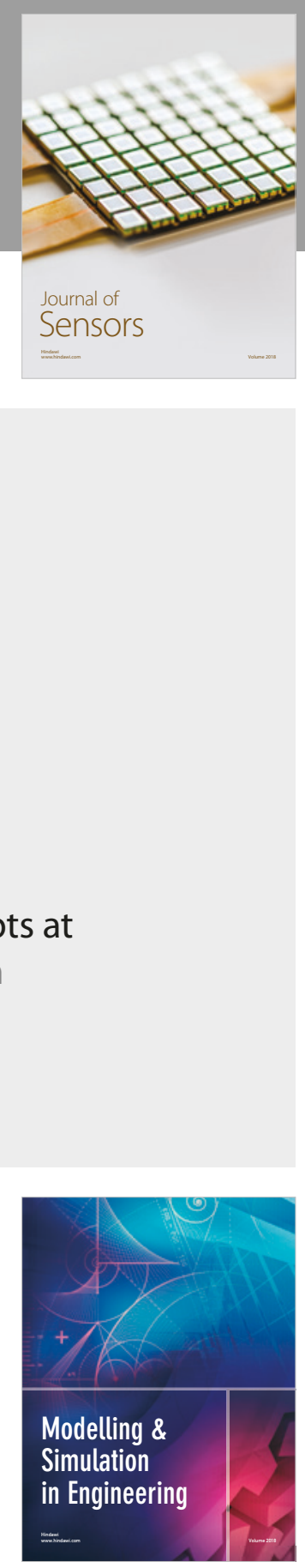

\section{Advances \\ Multimedia}
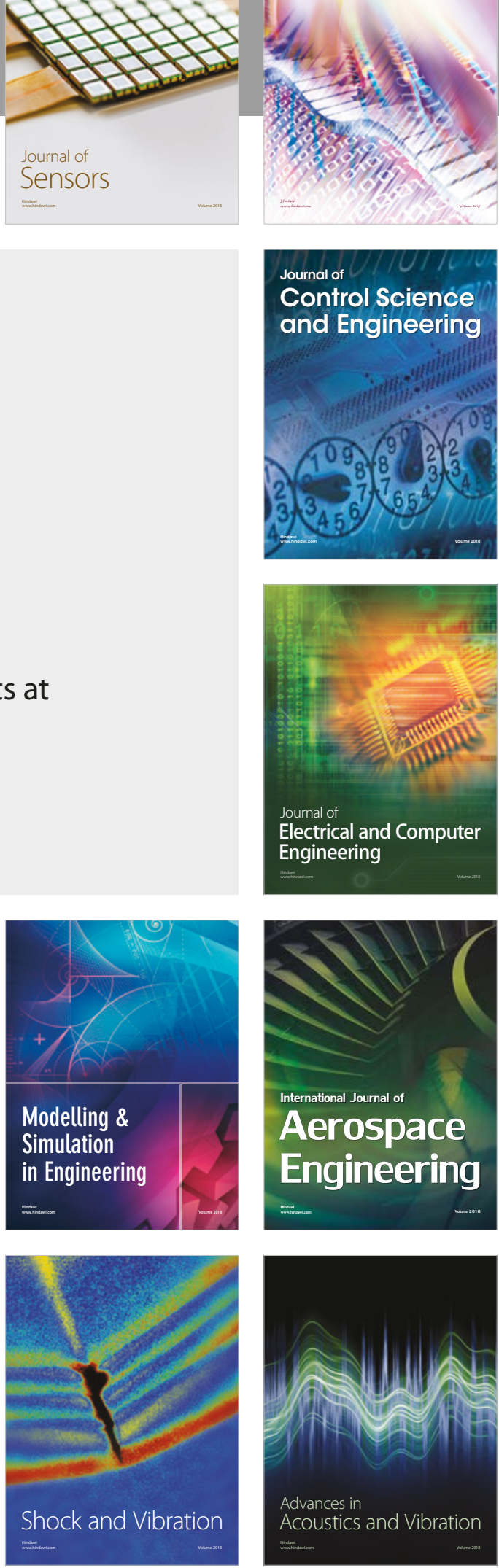